\section{The Effect of Temperature on Plant Growth in Four Gerbera hybrida Cultivars}

\author{
Fan Li, Shenchong Li, and Qinli Shan ${ }^{1}$ \\ Floriculture Research Institute, Yunnan Academy of Agricultural Sciences, \\ National Engineering Research Center for Ornamental Horticulture, Yunnan \\ Key Laboratory for Flower Breeding, Kunming 650200, China
}

Additional index words. temperature response, plant height, biomass accumulation, leaf area, photosynthesis

\begin{abstract}
Temperature is one of the main factors that affects the growth pattern of Gerbera hybrida, which shows vast variation in morphology and stress adaptation among cultivars. However, little is known about temperature responses of plant growth among different cultivars. In this study, four cultivars were planted in different growth temperatures to investigate the effect of temperature on plant growth of Gerbera hybrida during their vegetative growth. Results showed that the optimum growth temperature of the four cultivars was $20^{\circ} \mathrm{C}$, of which plant height, root length, biomass accumulation, leaf area, and photosynthetic rate were enhanced significantly. Different cultivars showed diverse temperature adaptation ranges, which were related with their genetic background, and the temperature adaptability of cultivar Autumn was the best among the four cultivars. Temperature also had significant effects on photosynthetic rate, which was the main factor shaping plant growth. Our research provides the basic guidance for the growth temperature control in the cultivation of Gerbera hybrida.
\end{abstract}

Gerbera hybrida is one of the most important floricultural plants worldwide due to the high variation of flower and inflorescence colors, which make it rank fourth in cut flowers after rose, chrysanthemum, and tulip according to data from the International Trade Center (Wani et al., 2018). Around the world, there are hundreds of Gerbera hybrida cultivars with extremely rich flower color patterns, including white, yellow, red, pink, purple, and brown. This is because commercial varieties of Gerbera hybrida are cultivated from the hybridization of two natural species: Gerbera jamesonii and Gerbera viridifolia (Hansen, 1999). For this highly heterozygous species, Gerbera hybrida naturally harbors the genetic diversity between different cultivars, causing distinct requirements in terms of growth conditions, such as temperature, light, moisture, and nutrients.

Temperature is a primary factor that affects plant growth, especially cell growth and elongation, and the process of growth can be differentiated by their temperature re-

Received for publication 20 Feb. 2019. Accepted for publication 1 Apr. 2019.

Supported by the Science and Technology Talents and Platform Program of Yunnan Province (2018HB117), China National Science and Technology Support Program (2015BAD10B01), the Key Research and Development (Agricultural field) Project of Yunnan Science and Technology Program (2018BB010), and the Major Science and Technology Project of Yunnan Province (2016ZA006).

${ }^{1}$ Corresponding author. E-mail: shqli2008@126. com. sponse in many cases (Takeshi and Amane, 2009). The effect of temperature on plant growth and development differs in each species, which has a specific temperature range (minimum, maximum, and optimum) during its life cycle (Hatfield and Prueger, 2015). For instance, the optimum temperature for vegetative development is $37^{\circ} \mathrm{C}$ and for reproductive development is $30{ }^{\circ} \mathrm{C}$ in cotton (Yuri et al., 2005), whereas in sorghum the optimum temperatures for vegetative and reproductive development are 34 and $31{ }^{\circ} \mathrm{C}$, respectively (Prasad et al., 2006). The changes of plant growth temperature induce a range of morphological responses and alternations in biomass allocation, and such changes lead to different temperature dependence of yields between species (Atkin et al., 2006). For example, the life cycle and duration of reproductive development were shorter under increased temperature, resulting in decreased grain yield in maize (Muchow et al., 1990); however, the biomass of rice increased with temperature (from 8 to $33^{\circ} \mathrm{C}$ ), and the optimum temperature for grain formation and yield was $25^{\circ} \mathrm{C}$ (Baker et al., 1995). Overall, the effect of temperature on plant growth and the underlying growth indices are different among species, and the mechanisms of growth temperature responses are still unclear.

Nevertheless, growth responses to temperature are not well known in Gerbera hybrida, even though this species has been used as an Asteraceae model plant for research on flower development and secondary metabolism for decades. Indeed, the factors that determine the differences in temperature-related growth traits between different cultivars are unclear. In this study, we aimed to characterize the different responses of plant growth and photosynthesis to temperature changes among four cultivars of Gerbera hybrida. We cultivated plant seedlings without soil using substrate (peat:perlite $=3: 1$ ) under four different temperature regimens: $15,20,25$, and $30^{\circ} \mathrm{C}$. We investigated plant growth parameters to analyze the temperature responses of plant growth, such as plant height, root length, aboveground weight, underground weight, and leaf area. The temperature response of the photosynthetic rate was also examined in fully expanded young leaves of each temperature regimen. The aim of this study was to provide scientific basis for the environmental control of soilless cultivation in Gerbera hybrida.

\section{Materials and Methods}

Plant material and growth conditions. Four commercial cultivars of Gerbera hybrida (Autumn, Pretty Pink, Lucky, and Yellow Storm; Fig. 1) were studied in this research. 'Lucky' and 'Yellow Storm' are the main cultivars in Yunnan Province, whereas cultivars Autumn and Pretty Pink are new varieties that were bred according to the climatic conditions of Yunnan. The four cultivars refer different phenotypes that adapted to low-latitude and high-altitude regions in Yunnan Province, China. Plant seedlings were obtained from Yuxi Yunxing Biological Technology Co., Ltd. (Yunnan Province, China) and planted separately in individual pots $($ diameter $=14 \mathrm{~cm}$, height $=$ $12 \mathrm{~cm}$ ) that were filled with commercial potting substrate (peat:perlite $=3: 1$ ). All seedlings were then cultivated in environmentally controlled growth chambers under the condition of $12 \mathrm{~h}$ photoperiod (photosynthetic photon flux density was $240 \mu \mathrm{mol} \cdot \mathrm{m}^{-2} \cdot \mathrm{s}^{-1}$ ) and $55 \%$ relative humidity in the laboratory of Yunnan Academy of Agricultural Sciences. The growth chamber (LRH-400-GSI, 400 L; Zhujiang, China) was controlled by microcomputer PID, with $\pm 1{ }^{\circ} \mathrm{C}$ and $\pm 8 \%$ control accuracy for temperature and humidity, respectively. The seedlings were treated with four different temperature regimes: 15, 20, 25 and $30{ }^{\circ} \mathrm{C}$, and each treatment used five individual seedlings as repetitions.

Plant growth analysis. Plant growth analysis were carried out on the 60th day after planting. The parameters of plant height, root length, aboveground weight, underground weight, leaf area, and photosynthetic rate were measured in each treatment. Leaf area was determined by a leaf area meter (LI-3100C; LI-COR, Lincoln, NE). Photosynthetic rate was measured by a fast-photosynthetic instrument (ECA-PC0401; Shanghai Danding International Trade Co., Ltd., China).

Statistical analysis. Data analysis and statistics were performed by Microsoft (Redmond, WA) Excel 2016 and Data Processing System (Hangzhou Ruifeng Information Technology Co., Ltd., China) (Tang and Zhang, 2013). One-way analysis of variance with post hoc Tukey honestly significant 
difference test were used for multiple samples mean comparison at the 5\% significant level.

\section{Results and Discussion}

Although Gerbera hybrida is mainly planted in modern greenhouses, and some of them are even equipped with a heating system, growth temperature is still the major factor that is considered by producers because of low night temperature during Winter. In this study, we examined the temperature responses of plant growth among four Gerbera hybrida cultivars, which showed large variations between temperature treatments and cultivars (Fig. 2, Supplemental Table 1). Generally, the optimum temperature for vegetative development of Gerbera hybrida was $20^{\circ} \mathrm{C}$, of which seedling growth was the strongest and photosynthetic rate was the greatest. However, different cultivars have their specific temperature limitation during vegetative development. For instance, the cultivar Pretty Pink could not survive at
$30{ }^{\circ} \mathrm{C}$, showing poor heat tolerance, whereas the cultivar Lucky was unable to resist cold because the seedlings were all dead at $15^{\circ} \mathrm{C}$. Only two cultivars examined in this study showed a wide range of temperature adaptability, from 15 to $30{ }^{\circ} \mathrm{C}$, which represents the climate condition in low-latitude and high-altitude regions in Yunnan Province. These differences may be caused by the diversity of the genetic background of the four cultivars, because each cultivar came from a different progress of hybrid breeding. A recent study of cold tolerance in Gerbera hybrida showed that cultivar Hongjixing could tolerate the extreme cold temperature of $-4{ }^{\circ} \mathrm{C}$ and keep flowering even below $0{ }^{\circ} \mathrm{C}$. The comparative transcriptome sequencing (RNA sequencing) revealed several pathways involved in the process of cold tolerance of Gerbera hybrida, such as carbon metabolism, nucleotide metabolism, secondary metabolism, transcription regulation, and stress defense-related responses ( $\mathrm{Li}$ et al., 2018). This indicates that a complex genetic and gene regulatory network controls the temperature resistance of Gerbera hybrida.

Further, from the view of plant height, the optimum temperature for all cultivars examined was $20^{\circ} \mathrm{C}$, which displayed a clear peak at that point (Fig. 2). More specifically, the cultivars Autumn and Yellow Storm showed the highest plant height at $20{ }^{\circ} \mathrm{C}$ compared with the other three temperatures, but no significant difference was observed between the two species in each four-temperature treatment, whereas the plant height of cultivars Pretty Pink and Lucky was significantly lower than that of cultivars Autumn and Yellow Storm. This is in line with their temperature tolerance trends. On the other hand, the four cultivars displayed no difference at 15 and $20^{\circ} \mathrm{C}$ in terms of root length, but significant differences were found at higher temperatures, indicating the root length is less sensitive to temperature changes. Moreover, the aboveground weight and underground weight of all cultivars gained the most at $20{ }^{\circ} \mathrm{C}$, indicating $20{ }^{\circ} \mathrm{C}$
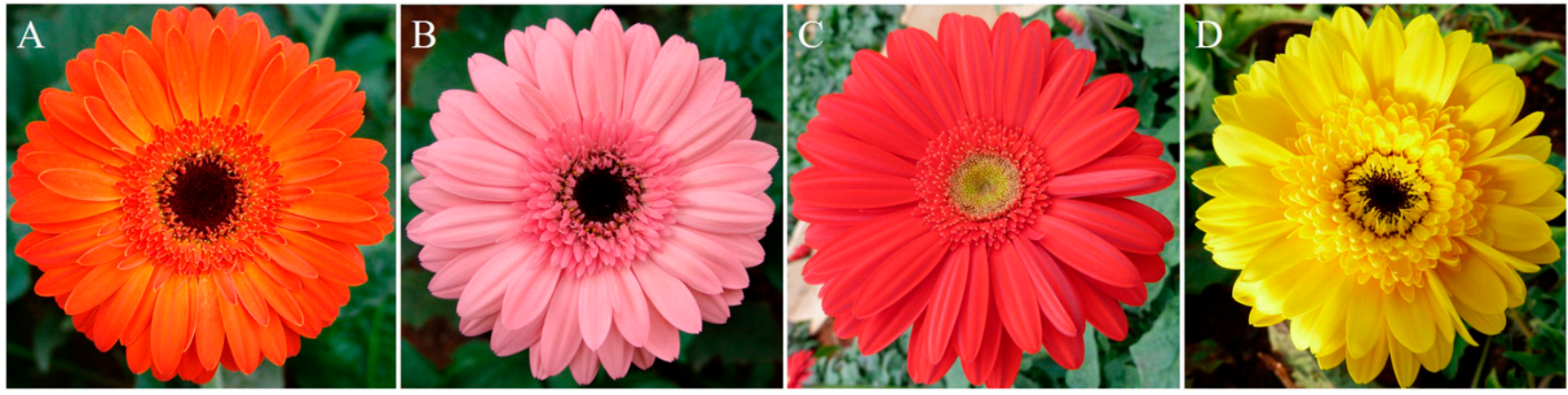

Fig. 1. Four commercial cultivars of Gerbera hybrida used in this study. (A) Gerbera hybrida cultivar Autumn; (B) Gerbera hybrida cultivar Pretty Pink; (C) Gerbera hybrida cultivar Lucky; (D) Gerbera hybrida cultivar Yellow Storm. The four cultivars refer to different phenotypes that adapted to low-latitude and high-altitude regions in Yunnan Province, China.
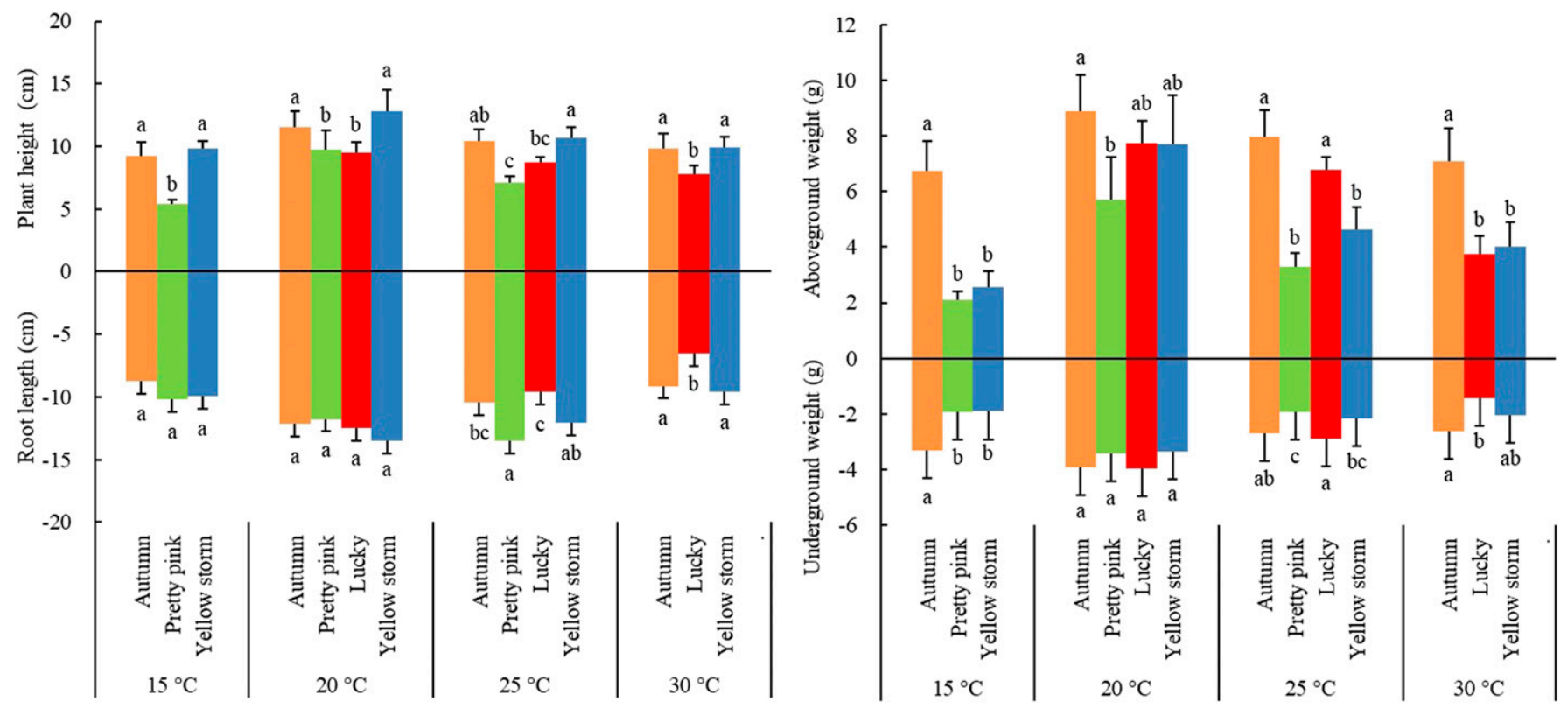

Fig. 2. Effects of temperature on plant growth in four cultivars of Gerbera hybrida (mean $\pm \mathrm{SD}, \mathrm{n}=5$ ). Small letters denote significant differences of growth parameters among the four cultivars at each temperature treatment. Statistical significance was analyzed based on one-way analysis of variance; $P$ value was calculated with post hoc Tukey honestly significant difference test $(\alpha=0.05)$. 
is the most suitable temperature for biomass accumulation in Gerbera hybrida (Fig. 2). Compared with other cultivars, the plant weight of cultivar Autumn was less sensitive to temperature changes, whereas cultivar Yellow Storm showed a dramatic change in plant weight, and cultivar Pretty Pink displayed the lowest biomass accumulation. Although no differences in plant height and root length were found in cultivars Yellow Storm and Autumn, the biomass accumulation of cultivar Yellow Storm was less efficient beyond the optimum temperature range. These data demonstrated that the temperature adaptability of cultivar Autumn is better than that of cultivar Yellow Storm.

Compared with photosynthetic rate, leaf area of the four cultivars did not show much variation in each temperature treatment, indicating temperature is not a key factor affecting leaf area among different cultivars
(Fig. 3). However, the photosynthetic rate of Gerbera hybrida was largely affected by temperature in the four cultivars, showing the lowest photosynthetic rate at $15{ }^{\circ} \mathrm{C}$ and highest at $20{ }^{\circ} \mathrm{C}$. Surprisingly, $5{ }^{\circ} \mathrm{C}$ increments stimulated more than 6-fold accumulation of photosynthetic rate, demonstrating temperature is the main factor determining photosynthetic rate in Gerbera hybrida. The study of temperature response of photosynthesis in transgenic rice showed that photosynthetic rate was predominantly limited by Rubisco capacity from 15 to $20^{\circ} \mathrm{C}$ (Makino and Sage, 2007). Consistent with this, several studies reported that Rubisco played a main role in the regulation of photosynthetic rate in many plant species, such as rice, spinach, and cyanobacteria (Fukayama et al., 2012; Kasai, 2010; Yamori et al., 2010; Zorz et al., 2015). Therefore, we speculate that the temperature responses of photosynthesis in Gerbera hybrida also may be related to Rubisco capacity, which needs further research for the principal factor limiting photosynthetic rate.

Our analysis revealed the responses of biomass accumulation, leaf area, and photosynthetic rate of the four cultivars to different temperature treatments, which showed the same trend with a peak at $20^{\circ} \mathrm{C}$. This pattern suggests a regulatory relationship between biomass accumulation and leaf area or photosynthetic rate. To explore this possibility, we next assessed the correlation between biomass and leaf area, as well as the correlation between biomass and photosynthetic rate. Indeed, the regression analysis revealed a significant correlation between biomass and leaf area $(P=0.0091)$, as well as the biomass and photosynthetic rate $(P=0.0272)$ (Fig. 4). This implies that the biomass accumulation of Gerbera hybrida is closely related to leaf
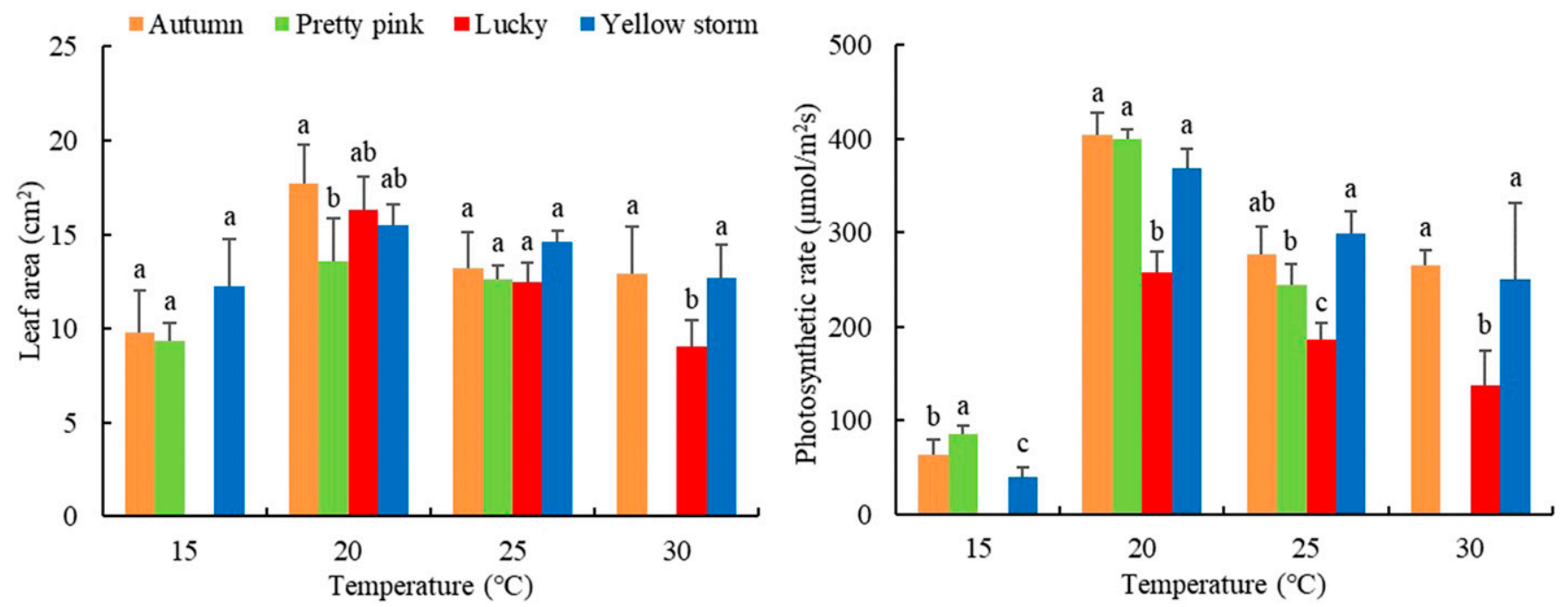

Fig. 3. Effects of temperature on leaf area and photosynthesis in four cultivars of Gerbera hybrida (mean $\pm \mathrm{SD}, \mathrm{n}=5$ ). Small letters denote significant differences of growth parameters among the four cultivars at each temperature treatment. Statistical significance was analyzed based on one-way analysis of variance; $P$ value was calculated with post hoc Tukey honestly significant difference test $(\alpha=0.05)$.
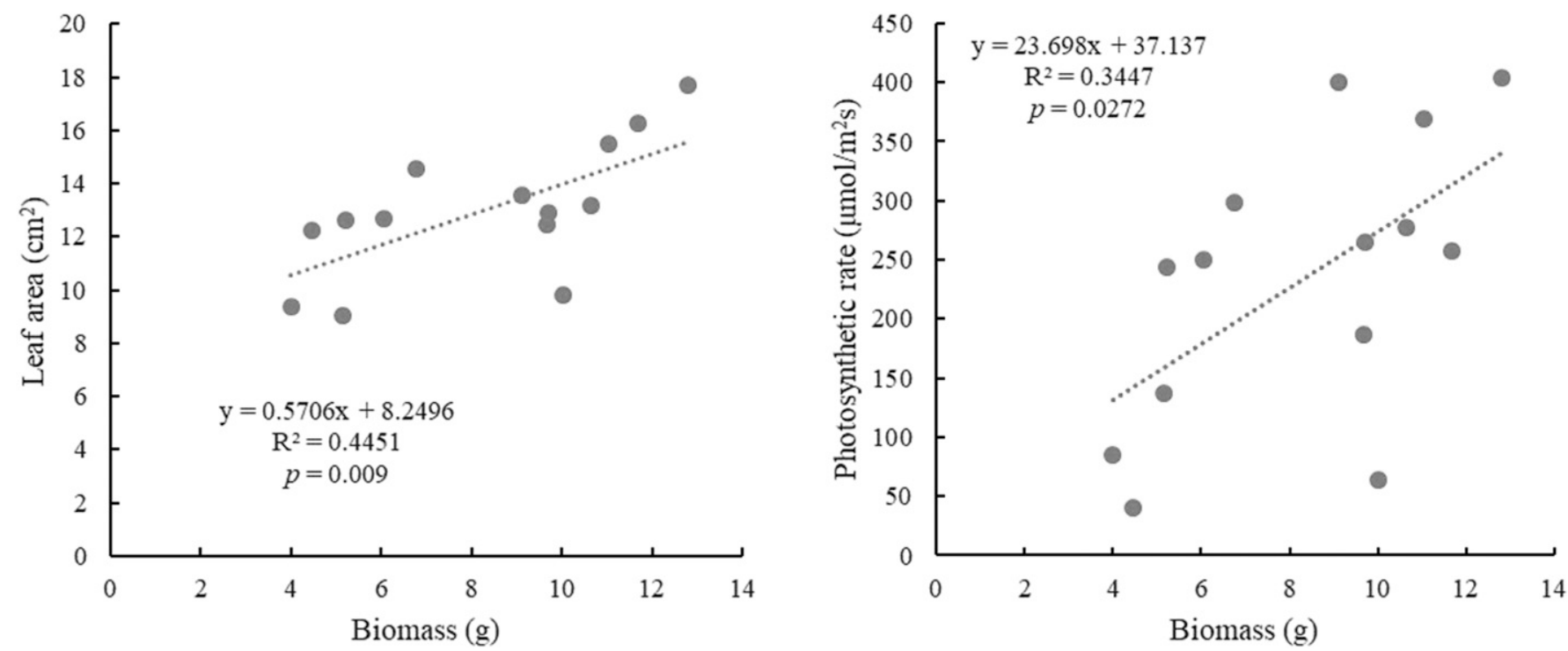

Fig. 4. The correlation analysis of biomass, leaf area, and photosynthetic rate in four cultivars of Gerbera hybrida $($ mean value, $\mathrm{n}=5$ ). 
area and photosynthetic rate. Overall, our research on the temperature tolerance of different cultivars could provide guidance for the production of Gerbera hybrida, but the molecular mechanisms underlying the tolerance still need further research to provide theoretical insights.

\section{Literature Cited}

Atkin, O.K., B.R. Loveys, L.J. Atkinson, and T.L. Pons. 2006. Phenotypic plasticity and growth temperature: Understanding interspecific variability. J. Expt. Bot. 57:267-281.

Baker, J.T., K.J. Boote, and L.H. Allen. 1995. Potential climate change effects on rice: Carbon dioxide and temperature, p. 31-47. In: C. Rosenzweig (ed.). Climate change and agriculture: Analysis of potential international impacts. American Society of Agronomy, Madison, WI.

Fukayama, H., C. Ueguchi, K. Nishikawa, N. Katoh, C. Ishikawa, C. Masumoto, T. Hatanaka, and S. Misoo. 2012. Overexpression of Rubisco activase decreases the photosynthetic $\mathrm{CO}_{2}$ assimilation rate by reducing Rubisco content in rice leaves. Plant Cell Physiol. 53:976-986.

Hansen, H.V. 1999. A story of the cultivated Gerbera. New Plantsman 6:85-95.
Hatfield, J.L. and J.H. Prueger. 2015. Temperature extremes: Effect on plant growth and development. Weather Clim. Extremes 10:4-10.

Kasai, M. 2010. Regulation of leaf photosynthetic rate correlating with leaf carbohydrate status and activation state of Rubisco under a variety of photosynthetic source/sink balances. Physiol. Plant. 134:216-226.

Li, S., Q. Shan, R. Yu, A.N. Siddique, X. Li, C. Yang, J. Ruan, and M. Li. 2018. Comparative transcriptome analysis of two Gerbera hybrida cultivars revealed cold tolerance mechanism. Plant Omics 11:10-19.

Makino, A. and R.F. Sage. 2007. Temperature response of photosynthesis in transgenic rice transformed with 'sense' or 'antisense' $r b c \mathrm{~S}$. Plant Cell Physiol. 48:1472-1483.

Muchow, R.C., T.R. Sinclair, and J.M. Bennett. 1990. Temperature and solar radiation effects on potential maize yield across locations. Agron. J. 82:338-343.

Prasad, P.V.V., K.J. Boote, and L.H. Allen, Jr. 2006. Adverse high temperature effects on pollen viability, seed-set, seed yield and harvest index of grain-sorghum [Sorghum bicolor (L.) Moench] are more severe at elevated carbon dioxide due to higher tissue temperatures. Agr. For. Meteorol. 139:237251.
Takeshi, N. and M. Amane. 2009. Differences between rice and wheat in temperature responses of photosynthesis and plant growth. Plant Cell Physiol. 50:744-755.

Tang, Q.Y. and C.X. Zhang. 2013. Data Processing System (DPS) software with experimental design, statistical analysis and data mining developed for use in entomological research. Insect Sci. 20:254-260.

Wani, M.A., I.T. Nazki, A. Din, S. Iqbal, S.A. Wani, and F. Khan. 2018. Floriculture sustainability initiative: The dawn of new era, p. 91-127. In: E. Lichtfouse (ed.). Sustainable Agriculture Reviews, vol. 27. Springer, Cham.

Yamori, W., K.K. Suzuki, M. Nakai, and I. Terashima. 2010. Effects of Rubisco kinetics and Rubisco activation state on the temperature dependence of the photosynthetic rate in spinach leaves from contrasting growth temperatures. Plant Cell Environ. 29:1659-1670.

Yuri, F., B. Vladimir, M. Igor, M. Valeri, and S. Oleg. 2005. Crop responses to elevated carbon dioxide and interaction with temperature. J. Crop Improv. 13:113-155.

Zorz, J., J. Allanach, C. Murphy, M. Roodvoets, D. Campbell, and A. Cockshutt. 2015. The Rubisco to photosystem II ratio limits the maximum photosynthetic rate in picocyanobacteria. Life 5:403-417. 


\begin{tabular}{|c|c|c|c|c|c|}
\hline \multirow[b]{2}{*}{ Cultivars } & \multirow[b]{2}{*}{ Parameters } & \multicolumn{4}{|c|}{ Temperature $\left({ }^{\circ} \mathrm{C}\right)$} \\
\hline & & 15 & 20 & 25 & 30 \\
\hline \multirow{4}{*}{ Autumn } & Root length $(\mathrm{cm})$ & $8.74 \pm 0.59 c$ & $12.16 \pm 0.71 \mathrm{a}$ & $10.44 \pm 0.53 b$ & $9.12 \pm 1.00 \mathrm{c}$ \\
\hline & Aboveground wt (g) & $6.72 \pm 1.09 \mathrm{~b}$ & $8.90 \pm 1.28 \mathrm{a}$ & $7.95 \pm 0.96 \mathrm{ab}$ & $7.10 \pm 1.17 \mathrm{ab}$ \\
\hline & Leaf area $\left(\mathrm{cm}^{2}\right)$ & $9.81 \pm 2.18 \mathrm{~b}$ & $17.69 \pm 2.09 \mathrm{a}$ & $13.19 \pm 1.93 \mathrm{~b}$ & $12.90 \pm 2.49 \mathrm{~b}$ \\
\hline & Photosynthetic rate $\left(\mu \mathrm{mol} \cdot \mathrm{m}^{-2} \cdot \mathrm{s}^{-1}\right)$ & $63.88 \pm 15.40 \mathrm{c}$ & $403.52 \pm 24.09 \mathrm{a}$ & $277.02 \pm 28.65 b$ & $265.18 \pm 16.21 \mathrm{~b}$ \\
\hline \multirow[t]{4}{*}{ Pretty Pink } & Plant height $(\mathrm{cm})$ & $5.40 \pm 1.23 \mathrm{~b}$ & $9.74 \pm 1.55 \mathrm{a}$ & $7.06 \pm 0.40 \mathrm{~b}$ & l \\
\hline & Underground wt (g) & $1.92 \pm 0.50 \mathrm{~b}$ & $3.43 \pm 0.86 \mathrm{a}$ & $1.93 \pm 0.20 \mathrm{~b}$ & / \\
\hline & Leaf area $\left(\mathrm{cm}^{2}\right)$ & $9.38 \pm 0.93 b$ & $13.57 \pm 2.29 \mathrm{a}$ & $12.60 \pm 0.75 \mathrm{a}$ & l \\
\hline & Photosynthetic rate $\left(\mu \mathrm{mol} \cdot \mathrm{m}^{-2} \cdot \mathrm{s}^{-1}\right)$ & $85.22 \pm 9.23 \mathrm{c}$ & $399.76 \pm 10.23 \mathrm{a}$ & $243.96 \pm 22.86 b$ & I \\
\hline \multirow{4}{*}{ Lucky } & Plant height (cm) & l & $9.49 \pm 0.75 \mathrm{a}$ & $8.72 \pm 0.94 \mathrm{ab}$ & $7.82 \pm 0.75 b$ \\
\hline & Root length $(\mathrm{cm})$ & 1 & $12.52 \pm 1.08 \mathrm{a}$ & $9.58 \pm 0.98 \mathrm{~b}$ & $6.52 \pm 0.70 \mathrm{c}$ \\
\hline & Aboveground wt (g) & / & $7.73 \pm 0.82 \mathrm{a}$ & $6.79 \pm 0.45 \mathrm{a}$ & $3.74 \pm 0.65 \mathrm{~b}$ \\
\hline & Underground wt (g) & 1 & $3.95 \pm 0.57 \mathrm{a}$ & $2.89 \pm 0.55 b$ & $1.42 \pm 0.26 \mathrm{c}$ \\
\hline \multirow{3}{*}{ Yellow Storm } & Underground wt (g) & $1.91 \pm 0.57 \mathrm{~b}$ & $3.35 \pm 0.43 \mathrm{a}$ & $2.15 \pm 0.20 \mathrm{~b}$ & $2.03 \pm 0.27 \mathrm{~b}$ \\
\hline & Leaf area $\left(\mathrm{cm}^{2}\right)$ & $12.25 \pm 2.48 \mathrm{~b}$ & $15.49 \pm 1.13 \mathrm{a}$ & $14.57 \pm 0.62 \mathrm{ab}$ & $12.69 \pm 1.77 \mathrm{ab}$ \\
\hline & Photosynthetic rate $\left(\mu \mathrm{mol} \cdot \mathrm{m}^{-2} \cdot \mathrm{s}^{-1}\right)$ & $39.70 \pm 9.67 \mathrm{c}$ & $368.98 \pm 19.80 \mathrm{a}$ & $298.32 \pm 24.31 \mathrm{ab}$ & $250.48 \pm 80.17 \mathrm{~b}$ \\
\hline
\end{tabular}

Lowercase letters denote significant differences of growth parameters among four temperature treatments of each cultivar. Statistical significance was analyzed based on one-way analysis of variance; $P$ value was calculated with post hoc Tukey honestly significant difference test $(\alpha=0.05)$. 